\title{
Degree of control of physician- diagnosed asthma and COPD in Italy
}

\author{
G. Caramori1, G. Bettoncelli2, M. Carone3, R. Tosatto4, \\ P. Di Blasi4, A. Pieretto4, G. Invernizzi², B. Franco Novelletto2, \\ A. Ciaccia 1 , I.M. Adcock5, A. Papi 1
}

ABSTRACT: Degree of control of physician-diagnosed asthma and COPD in Italy. G. Caramori, G. Bettoncelli, M. Carone, R. Tosatto, P. Di Blasi, A. Pieretto, G. Invernizzi, B. Franco Novelletto, A. Ciaccia, I.M. Adcock, A. Papi. Background. It is important for the Italian National Health Service to obtain data on the degree of control of asthma and chronic obstructive pulmonary disease (COPD) in the general population in Italy in order for balanced planning of future investments in these diseases to be made. Currently, precise estimates of these parameters are not available in literature.

Objectives. In collaboration with the Italian Academy of General Practitioners (SIMG; www.simg.it) we have investigated the degree of control of physician-diagnosed asthma and COPD in Italy.

Methods. A standardised questionnaire on asthma and COPD has been self-administered to a sample of 1937 Italian family physicians (representing around 5\% of all the Italian doctors involved in general practice) chosen to cover all the Italian counties.

Results. We have collected questionnaire data from 19,917 patients with asthma and COPD followed in their practice and $12,438(62.4 \%)$ were correctly filled in enabling evaluation. We selected the number of emergency room visits, hospitalisations and intensive care unit admissions for asthma and COPD in the last 12 months as objective measures of the degree of asthma and COPD morbidity in these patients. The figures were respectively $12.4 \%$ (emergency room visits), $17.3 \%$ (hospitalisations) and $\mathbf{1 . 2 \%}$ (intensive care unit admissions) of all patients with physician-diagnosed asthma and COPD.

Conclusions. This data suggests that in Italy the morbidity of asthma and COPD remains high; representing a significant burden for the Italian National Health Service. There is a clear necessity for further studies to investigate the causes of this incomplete control.

Monaldi Arch Chest Dis 2007; 67: 1, 15-22.

Keywords: General practitioners, asthma, COPD, hospital admission, exacerbation, control.

1 Centro di Ricerca su Asma e BPCO, University of Ferrara,

2 Gruppo CORDIS on behalf of the Società Italiana di Medicina Generale (SIMG), Firenze,

3 Divisione di Pneumologia Riabilitativa, Fondazione Salvatore Maugeri, I.R.C.C.S., Veruno (NO),

4 Direzione Medica, GlaxoSmithKline, Verona, Italy.

5 Airway Disease Section, National Heart and Lung Institute, Imperial College London, UK.

Correspondence: Gaetano Caramori MD, PhD; Centro di Ricerca su Asma e BPCO, Via Savonarola 9, University of Ferrara, 44100 Ferrara, Italy; e-mail: crm@unife.it

This work has been funded by GSK (Italy).

\section{Introduction}

A measure of the degree of control of bronchial asthma and chronic obstructive pulmonary disease (COPD) in the general population in Italy is important to enable the Italian National Health Service to plan for future investments in these diseases. Although the extent to which asthma and COPD is controlled in the adult Italian general population is currently unknown, many studies, targetting small subgroups of patients with asthma or COPD, suggest that insufficient control of asthma and COPD is still a significant problem for the health care services in Italy [1-4] despite International guidelines for the treatment of asthma (Global Strategy for Asthma Management and Prevention, GINA) and COPD (Global Initiative for Chronic Obstructive Lung Disease, GOLD) $[5,6]$.
However, precise estimates of the degree of control of physician-diagnosed asthma and COPD in Italy in the adult general population are not available in the literature. On the basis of this observation, the Respirology group of the Italian Academy of General practitioners (Società Italiana di Medicina Generale (SIMG); www.simg.it), has carried out an observational cross-sectional study, under the acronym CORDIS (Chronic Obstructive Respiratory Disease - Italian Study), with the aim of evaluating the knowledge and the degree of control of physician-diagnosed asthma and COPD by Italian general practitioners. This study consisted of two phases (CORDIS-A and CORDIS-B). The design of the CORDIS-A study and its results has already been reported [7]. The design of CORDIS-B and its results on the degree of control of physician-diagnosed asthma and COPD are reported here. The remaining results will be the subject of future communications. 


\section{Methods}

The CORDIS-B study was carried out between April 2002 and May 2002 and involved 1,937 general practitioners (representing around $5 \%$ of all the Italian doctors involved in general practice). They have been chosen by the SIMG to cover all the Italian counties and for their willingness to participate at the study (fig. 1). Patients enrolled in the study were males and females aged over18 years, with a physician (general practitioner or specialist) diagnosis of asthma and/or COPD and treated from at least 12 months with a short-term inhaled $\beta_{2}$-agonist, given alone or as component of a multiple therapy.

The patients studied included both self referrals and those actively recruited by their physician.

For each patient enrolled, data was collected by two different questionnaires: one completed by the general practitioner and the other privately completed by the patient. This paper only includes data from the questionnaire filled in by the general practitioners (Appendix 1). Both the Italian version and the English translation of this questionnaire are freely available online at (http://www. simg.it/pneumo/attivita/cordis/CORDISBquestionnaireItalianphysician.pdf) and (http://www. simg.it/pneumo/attivita/cordis/CORDISBquestionnaireEnglishphysician.pdf).
This questionnaire was divided into three sections: the first section dealt with the patient details (smoking habit, concomitant diseases, spirometry and/or skin prick tests, physician-diagnosed asthma and/or COPD, criterion used for asthma and/or COPD severity staging), the second section dealt with the pharmacological treatment used by the patient in the last 12 months (short- and/or longacting inhaled $\beta_{2}$-agonists, inhaled and/or systemic glucocorticoids, combination of these drugs in a single inhaler, antileukotrienes, theophylline, cromones, antihistamines, mucolytics, anticholinergics, antibiotics); the third section dealt with the degree of control of patients affected by asthma and COPD in the last 12 months (number of specialist visits, number of emergency room visits, number of hospitalisations, number of intensive care unit admissions).

As objective measures of the degree of asthma and COPD morbidity in these patients we chose the number of emergency room visits, hospitalisations and intensive care unit admissions for asthma and COPD in the last 12 months before the entry into the study. This data was obtained from the GPs electronic data base and based on the patient discharge letter after their emergency room visit or hospitalisation.

A descriptive statistical analysis was carried out using the statistical package "STATISTICA"

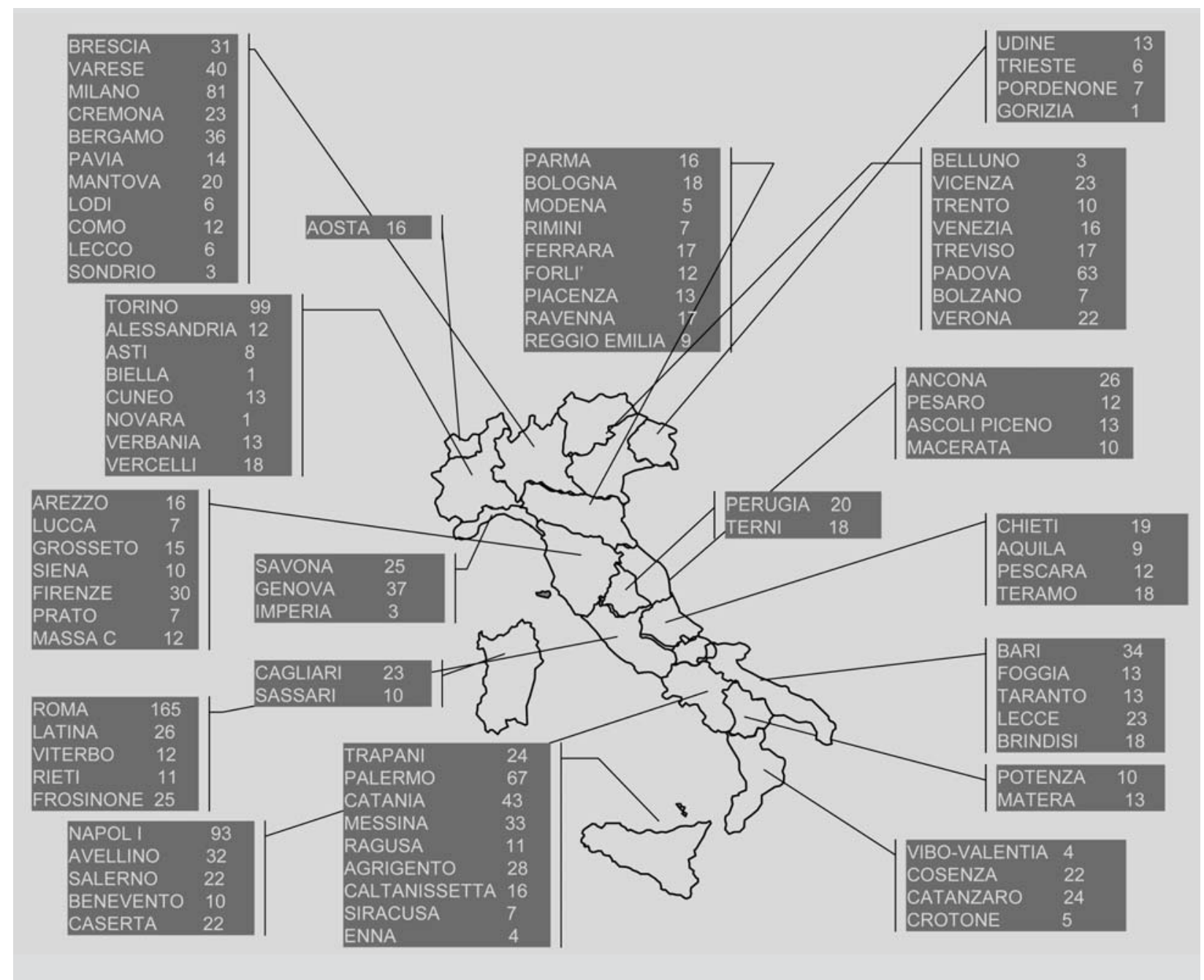

Fig. 1. - Distribution within Italy of general practitioners participating to the study. 
(Statsoft Italia; http://www.statsoft.com/italian /home_it.html). It was a bi-variate analysis comparing the physicians' diagnosis with the patients' variables. $p$ values are derived from the ChiSquare test for comparison between incidence of severe asthma and COPD exacerbations in patients with persistent asthma and moderate to severe COPD, treated or not according to GINA or GOLD guidelines respectively.

\section{Results}

A total of 19,921 questionnaires were collected, and $12,438(62.4 \%)$ were evaluated having been successfully completed by the general practitioners.

When divided according to their geographical area, $42 \%$ of the general practitioners were resident in the North, 25\% in Central Italy and 33\% in the South and Islands (fig. 1). Most of the patients $(73.5 \%)$ enrolled in the study were self referrals to the general practitioners' offices, the remaining were recalled by their physician. The mean age of the sample of asthma and/or COPD patients that completed the questionnaire was $56.9 \%( \pm 17.4)$ years, with a prevalence of males $(55 \%)$. Nonsmokers, smokers and ex-smokers represented respectively $47.7 \%, 27.5 \%$ and $23.8 \%$ of the patients. The general characteristics of study population are summarised in table 1 . The percentage of patients with asthma, COPD and asthma plus COPD was $46.2 \%, 28.6 \%$ and $22.8 \%$ respectively.

In terms of the stages of the disease's severity, COPD was mild in $16.1 \%$ of patients, moderate in $53.5 \%$ of patients and severe in $28.3 \%$ of patients. In most COPD patients $(66.2 \%)$, the level of severity was defined according to symptom frequency together with the level of airflow obstruction measured by spirometry. However in $24.9 \%$ of cases the physician used only the symptom frequency as a measure of severity and, furthermore, in $8.9 \%$ of cases the physician used only the level of airflow obstruction as measured by spirometry.

Asthma was defined as intermittent, mild persistent, moderate persistent and severe persistent respectively in $38.1 \%, 26.3 \%, 28.4 \%$ and $5 \%$ of subjects respectively. For asthmatic patients, the criteria used by the physician to judge disease severity was symptom frequency in $42.1 \%$ of patients, whilst in $53.6 \%$ of subjects symptom frequency together with the level of airflow obstruction as measured by spirometry was used. Finally, in $4.3 \%$ of cases the physician used only the level of airflow obstruction as measured by spirometry.

In $2.1 \%$ of patients with either asthma or COPD, the disease severity was not reported.

All patients were taking short-acting inhaled $\beta_{2}$-agonists, either administered alone or in a combination product, according to the inclusion criteria. The most frequently used additional drugs in the previous 12 months were: oral antibiotics (53.9\% of patients), mucolytics $(38.1 \%)$, combined inhaled $\beta_{2}$-agonists/glucocorticoids (35.5\%), inhaled glucocorticoids $(26.7 \%)$. We found a significantly increased use in the previous 12 months of theophylline $(32.6 \%$ vs $9.9 \%$; $<<0.001)$, mucolytics $(49.7 \%$ vs $21.9 \%$; $\mathrm{p}<0.001)$ and oral antibiotics $(64.1 \%$ vs $38.2 \%$; $p<0.001)$ in COPD patients compared with asthmatics. In contrast, the use of histamine receptor antagonists $(27.7 \%$ vs $6.1 \% ; \mathrm{p}<0.001)$ and antileukotrienes $(14.5 \%$ vs $5.9 \% ; p<0.001$ ) was significantly more frequent in asthmatic compared with COPD patients. Considering only the patients with a diagnosis of moderate to severe persistent asthma $(n=3,288)$, only $1,817(55.3 \%)$ were treated with long-acting inhaled $\beta_{2}$-agonists together with inhaled glucocorticoids according to the GINA guidelines. When patients with persistent asthma or moderate to severe COPD and at least one severe asthmatic or COPD exacerbation in the last 12 months before the entry in the study were stratified according to the presence or absence of inhaled glucocorticoids or regular bronchodilator treatment respectively, we have found that patients with mild persistent asthma not treated with inhaled glucocorticoids had an increased percentage of severe asthmatic exacerbations (emergency room visits and hospital admissions) in the 12 months preceding their entry into the study (tables 2A and 2B). In addition, patients with moderate COPD not on regular treatment with bronchodilators had an increased percentage of severe COPD exacerbations (emergency room visits and hospital admissions) in the last 12 months before the entry in the study (tables $3 \mathrm{~A}$ and $3 \mathrm{~B}$ ). However, unexpectedly, patients with severe persistent asthma or severe COPD had an increased percentage of severe asthma and COPD exacerbations in the subgroup of subjects prescribed inhaled therapy according to guidelines versus patients without correct treatment (tables $3 \mathrm{~A}$ and $3 \mathrm{~B}$ ). The number of ICU admissions for both asthma and COPD were too low to allow for formal statistical comparison.

Table 1. - General characteristics of the study population

\begin{tabular}{|c|c|c|c|c|c|c|c|c|}
\hline \multirow{2}{*}{$\begin{array}{r}\text { Total nr } \\
12,438\end{array}$} & \multirow{2}{*}{$\begin{array}{c}\begin{array}{c}\text { Mean age } \\
\text { years }(\mathrm{SD})\end{array} \\
56.9(17.4)\end{array}$} & \multirow{2}{*}{\multicolumn{2}{|c|}{$\begin{array}{ll} & \begin{array}{c}\text { Sex } \\
\mathbf{n}(\%)\end{array} \\
\text { M } & 6,845(55.0)\end{array}$}} & \multirow{2}{*}{$\begin{array}{l}\text { Subjects' access modality } \\
\text { n }(\%)\end{array}$} & \multicolumn{2}{|c|}{$\begin{array}{c}\text { Smoking habits } \\
\text { n (\%) }\end{array}$} & \multicolumn{2}{|c|}{$\begin{array}{c}\text { Diagnosis } \\
\mathbf{n}(\%)\end{array}$} \\
\hline & & & & & Non-smokers & $5,931(47.7)$ & Asthma & $5,751(46.2)$ \\
\hline & & $\mathrm{F}$ & $5,294(42.6)$ & 3,071 (24.5) & Current smokers & $3,417(27.5)$ & COPD & 3,559 (28.6) \\
\hline & & N/A & $299(2.4)$ & $227(2)$ & Ex-smokers & $2,966(23.8)$ & Asthma+COPD & $2,834(22.8)$ \\
\hline & & & & & N/A & $124(1)$ & N/A & $294(2.4)$ \\
\hline
\end{tabular}

Definition of abbreviations: $\mathrm{SD}=$ standard deviation; $\mathrm{N} / \mathrm{A}=$ not available; $\mathrm{M}=$ male; $\mathrm{F}=$ female $\mathrm{COPD}=$ chronic obstructive pulmonary disease 
Table 2A. - Patients with persistent asthma with at least one emergency room visit in the last 12 months stratified according to the presence or absence of regular inhaled glucocorticoid treatment

\begin{tabular}{|c|c|c|c|c|}
\hline & \multicolumn{3}{|c|}{ Emergency room visit in the last 12 months } & \multirow[t]{2}{*}{$p$-value } \\
\hline & $\mathbf{G C}+(\mathbf{N}, \%)$ & vs & GC- $(\mathbf{N}, \%)$ & \\
\hline Total $(\mathrm{N}=373)$ : & $241(65 \%)$ & vs & $132(35 \%)$ & \\
\hline Mild persistent asthma & $39(16.2 \%)$ & vs & $35(26.5 \%)$ & $p<0.05$ \\
\hline Moderate persistent asthma & $138(57.3 \%)$ & vs & $76(57.6 \%)$ & $\mathrm{p}=\mathrm{n} . \mathrm{s}$. \\
\hline Severe persistent asthma & $64(26.5 \%)$ & vs & $21(15.9 \%)$ & $p<0.05$ \\
\hline
\end{tabular}

$\mathrm{GC}=$ inhaled glucocorticoids. Data is expressed as total number $(\mathrm{N})$ and percentage $(\%)$ of patients.

$p$ values are derived from the $C h i$-Square test.

Table 2B. - Patients with persistent asthma with at least one hospitalisation in the last 12 months stratified according to the presence or absence of regular inhaled glucocorticoid treatment

\begin{tabular}{lllll}
\hline & \multicolumn{3}{c}{ Hospitalisation } & \multirow{2}{*}{-value } \\
& GC+(N,\%) & vs & GC-(N, \%) & \\
\hline Total (N=277): & $169(61 \%)$ & vs & $108(59 \%)$ & \\
Mild persistent asthma & $24(14.2 \%)$ & vs & $33(30.6 \%)$ & $p<0.001$ \\
Moderate persistent asthma & $80(47.3 \%)$ & vs & $51(47.2 \%)$ & $p=n . s$. \\
Severe persistent asthma & $65(38.5 \%)$ & vs & $24(22.2 \%)$ & $p<0.001$ \\
\hline
\end{tabular}

$\mathrm{GC}=$ inhaled glucocorticoids. Data is expressed as total number $(\mathrm{N})$ and percentage $(\%)$ of patients.

$p$ values are derived from the Chi-Square test.

Table 3A. - Patients with moderate to severe COPD and at least one emergency room visit in the last 12 months stratified according to the presence or absence of regular treatment with bronchodilators

\begin{tabular}{lcccc}
\hline & \multicolumn{3}{c}{ Emergency room visit } & \multirow{2}{*}{-value } \\
& BD+(N,\%) & vs & BD-(N, \%) & \\
\hline Total (N=432): & $354(82 \%)$ & vs & $78(18 \%)$ & \\
Moderate COPD & $142(40.1 \%)$ & vs & $56(71.8 \%)$ & $p<0.001$ \\
Severe COPD & $212(59.9 \%)$ & vs & $22(28.2 \%)$ & $p<0.001$ \\
\hline
\end{tabular}

$\mathrm{BD}=$ bronchodilators. Data is expressed as total number $(\mathrm{N})$ and percentage $(\%)$ of patients.

$p$ values are derived from the Chi-Square test.

Table 3B. - Patients with moderate to severe COPD and at least one hospitalisation in the last 12 months stratified according to the presence or absence of regular treatment with bronchodilators

\begin{tabular}{lllll}
\hline & \multicolumn{3}{c}{ Hospitalisation } & \multirow{2}{*}{-value } \\
& BD+(N,\%) & vs & BD-(N, \%) & \\
\hline Total (N=849): & $700(82.5 \%)$ & vs & $149(17.5 \%)$ & \\
Moderate COPD & $261(37.3 \%)$ & vs & $85(57.1 \%)$ & $P<0.001$ \\
Severe COPD & $439(62.7 \%)$ & vs & $64(42.9 \%)$ & $P<0.001$ \\
\hline
\end{tabular}

$\mathrm{BD}=$ bronchodilators. Data is expressed as total number $(\mathrm{N})$ and percentage $(\%)$ of patients.

$p$ values are derived from the Chi-Square test.

Considering only the patients with a diagnosis of moderate to severe COPD $(n=4,985)$, only $2,425(48.6 \%)$ were treated with long-acting inhaled $\beta_{2}$-agonists together with inhaled glucocorticoids according to the GOLD guidelines. Around half $(50.3 \%)$ of all patients had at least one specialist visit in the 12 months before their entry into the study.
The percentage of patients with at least one severe exacerbation (defined as hospitalisation or emergency room visit or intensive care unit in the 12 months before their entry into the study) were respectively $17.5 \%$ (hospitalisations), $12.5 \%$ (emergency room visits) and $1.2 \%$ (intensive care unit admissions) (table 4). Table 5 demonstrates the number of patients with severe asthmatic or 
Table 4. - Patients with at least one severe asthma or COPD exacerbation in the last 12 months

\begin{tabular}{lcccc}
\hline & $\begin{array}{c}\text { Asthma } \\
(\mathbf{N = 5 , 7 5 1 )} \\
\mathbf{N}(\mathbf{\%})\end{array}$ & $\begin{array}{c}\text { COPD } \\
(\mathbf{N = 3 , 5 5 9 )} \\
\mathbf{N}(\mathbf{\%})\end{array}$ & $\begin{array}{c}\text { Asthma and COPD } \\
(\mathbf{N = 2 , 8 3 4 )} \\
\mathbf{N}(\mathbf{\%})\end{array}$ & $\begin{array}{c}\text { Total } \\
(\mathbf{N = 1 2 , 1 4 4}) * \\
\mathbf{N}(\mathbf{\%})\end{array}$ \\
\hline Emergency room visit & $\begin{array}{c}48 \\
(8.5)\end{array}$ & $\begin{array}{c}490 \\
(13.7)\end{array}$ & $\begin{array}{c}545 \\
(19.2)\end{array}$ & $\begin{array}{c}1524 \\
(12.5)\end{array}$ \\
\hline Hospitalisation & 343 & 917 & 873 & 2,133 \\
& $(5.9)$ & $(25.8)$ & $(30.8)$ & $(17.5)$ \\
\hline ICU admission & 15 & 58 & 76 & 149 \\
& $(0.3)$ & $(1.6)$ & $(2.7)$ & $(1.2)$ \\
\hline
\end{tabular}

The data is expressed as total number $(\mathrm{N})$ and percentage $(\%)$ of patients.

$\mathrm{COPD}=$ chronic obstructive pulmonary disease; ICU = intensive care unit. * For 294 patients diagnosis was not reported.

Table 5. - Patients with at least one severe asthmatic or COPD exacerbation in the last 12 months stratified according to their level of severity

\begin{tabular}{|c|c|c|c|}
\hline & $\begin{array}{c}\text { Emergency room visit } \\
\mathbf{N}(\%)\end{array}$ & $\begin{array}{l}\text { Hospitalisation } \\
\text { N (\%) }\end{array}$ & $\begin{array}{c}\text { ICU admission } \\
\mathbf{N}(\%)\end{array}$ \\
\hline \multicolumn{4}{|l|}{ Asthma } \\
\hline Total & 489 & 343 & 15 \\
\hline Intermittent & $103(21.1)$ & $55(16.0)$ & $2(13.3)$ \\
\hline Mild persistent & $74(15.1)$ & 57 (16.6) & $3(20.0)$ \\
\hline Moderate persistent & $214(43.8)$ & $131(38.2)$ & $8(53.4)$ \\
\hline Severe persistent & $85(17.4)$ & $89(26.0)$ & 2 (13.3) \\
\hline N/A & $13(2.6)$ & $11(3.2)$ & $0(0.0)$ \\
\hline \multicolumn{4}{|l|}{ COPD } \\
\hline Total & 490 & 917 & 58 \\
\hline Mild & $29(6.0)$ & $26(2.8)$ & $5(8.6)$ \\
\hline Moderate & $198(40.4)$ & $346(37.8)$ & $10(17.3)$ \\
\hline Severe & $234(47.7)$ & $503(54.8)$ & $41(70.7)$ \\
\hline N/A & $29(5.9)$ & $42(4.6)$ & $2(3.4)$ \\
\hline
\end{tabular}

$\mathrm{N}(\%)=$ number (percentage) of patients; ICU=intensive care unit; $\mathrm{N} / \mathrm{A}=$ data on staging not reported; $\mathrm{COPD}=$ chronic obstructive pulmonary disease.

COPD exacerbations in the last 12 months stratified accordingly to their level of severity.

\section{Discussion}

The current study shows that a high number of patients with asthma and COPD have poor control of their disease. This data is in keeping with the results of previous studies conducted on small subgroups of Italian adult patients with asthma or COPD. For example, the Asthma Insights and Reality in Europe (AIRE) survey, a multi-national survey assessing the level of asthma control from the patients perspective in seven Western European countries, previously demonstrated that the GINA guideline goals were not achieved in Italy and that adult asthmatics are poorly controlled in a significant proportion of all cases examined [3]. Using the ratio of recent inhaled glucocorticoid use to recent short-acting inhaled $\beta_{2}$-agonist use as an index of asthma control, another study reported inadequate use of controller medication (ratio <1) among severe asthmatic patients. This disparity was greatest among adults in Italy and France, where recent inhaled glucocorticoid use was reported by less than one in nine patients reporting recent use of short-acting bronchodilators [8]. Another largescale international survey, named "Confronting COPD in North America and Europe", assessed clinical outcomes, use of healthcare resources and loss of productivity in the workplace, and the economic cost of this disease in Italy and six other countries. Three-quarters of the direct patient costs of COPD in Italy were accounted for by hospitalisations, suggesting that interventions aimed at preventing exacerbations could alleviate the economic burden of COPD in Italy $[1,2]$. The high impact of COPD on the Italian National Health Service is also likely to be a consequence of the underdiagnosis and undertreatment of the disease, suggesting that costs may be reduced by increasing the utilisation of spirometry as a diagnostic tool, and improving physician adherence to treatment guidelines $[1,2]$.

There are many possible explanations behind the incomplete control of asthma and COPD in the adult general population in Italy. 
During the last 20 years our knowledge of the pathogenesis of asthma and COPD has made enormous advances, significantly changing the diagnostic approach and treatment. According to the evidence-based medicine approach, this new knowledge has been structured in National and International guidelines $[5,6]$. Released under the auspices of the World Health Organisation (WHO) GINA and GOLD guidelines aim to obtain a better control of bronchial asthma and COPD in the general population. These guidelines have already been translated in Italy (respectively under the headings "Progetto Mondiale asma" and "Progetto Mondiale BPCO") and approved by all the leading scientific societies in Italy involved in the treatment of patients with asthma and COPD $[5,6]$.

However, many studies have shown that guidelines, although disseminated among healthcare providers, are rarely applied in primary care [9]. There are, in fact, several reasons to suspect that Italian general practitioners' knowledge and adherence to recommended guidelines on asthma and COPD is modest at best [7]. In addition, the use of COPD guidelines was not associated with improved control of the disease in a general practice study in Italy [10]. Thus, the implementation of evidence-based clinical recommendations by physicians in office settings is limited both by patient preferences and by physician factors that are poorly understood [9].

Poor compliance with inhaled therapy is another major problem that has shown to cause loss of control of asthma and COPD in many controlled studies $[11,12]$. Unfortunately, our study was not planned to measure patient compliance with asthma and COPD medications so in the current study we were unable to verify its importance in the degree of control of asthma and COPD. Another possibility, that cannot be discarded, is that despite the enormous advances in the control of the morbidity and mortality of asthma there is still a significant proportion of severe asthmatic exacerbations that cannot be fully prevented by current treatment in the general adult population. For example there is emerging data on partial steroid insensitivity of virus-induced asthma exacerbations and these are often severe [13]. In addition the drugs currently available for the regular long-term treatment of COPD are unable to completely prevent severe COPD exacerbations [14]. Our study has clearly many limitations. The major limitation is represented by the classification of the level of severity of asthma and COPD. Accordingly to GINA and GOLD guidelines it should be based both on symptoms and/or lung function tests and, for asthma, also on the pharmacological class and dosage of drugs needed to control asthma $[5,6]$. We have simply collected a classification based on GPs own judgment with no objective verification of the real level of severity. As a matter of fact, we have found contradictory data. Globally, there is an increased number of patients with severe asthma or COPD exacerbation treated with inhaled glucocorticoids or long-acting bronchodilators respectively, as compared with sub- jects not prescribed a correct treatment. When these patients are stratified according to their level of severity, patients with mild persistent asthma not treated with inhaled glucocorticoids have an increased percentage of severe asthmatic exacerbations (emergency room visits and hospital admissions) in the 12 months preceding entry into the study as well as patients with moderate COPD not on regular treatment with bronchodilators have an increased percentage of severe COPD exacerbations (emergency room visits and hospital admissions) in the last 12 months before entry into the study. However, surprisingly, patients with severe persistent asthma or severe COPD receiving an inhalator treatment based on international guidelines have an increased percentage of severe asthma and COPD exacerbations in comparison with subjects not receiving inhaled corticosteroids or long-acting bronchodilators respectively. This data suggests that GPs may misunderstand and misclassify the real level of severity of these diseases and are consequently not modifying the pharmacological treatment accordingly. This also may explain the poor control of asthma and COPD in these patients. Another significant limitation of our study is the absence of objective verification of the severe exacerbations of asthma and COPD. This data is usually stored in the electronic data base of the GPs derived from the discharge letter of the patients after their emergency room visit or hospitalisation and the importance of this information has been repeatedly stressed in the meeting with the local (regional) coordinators of the study. However, we cannot discard the possibility that an unknown percentage of the emergency room visits, hospitalisations and ICU admissions labelled in this study as severe asthma and COPD exacerbations were actually caused by other diseases. This area clearly deserves more research. As expected, we found a significantly increased use in the previous 12 months of theophylline, mucolytics and oral antibiotics in COPD patients compared with asthmatics. However it is worth noting the high percentage of asthmatic patients who had a prescription of mucolytics and oral antibiotics (respectively $21.9 \%$ and $38.2 \%$ of all asthmatics) whereas the GINA guidelines do not recommend the use of these drugs for asthmatics [5] suggesting again a low adherence to the guidelines. Also it should be noted that antileukotrienes have been prescribed in the previous 12 months to $5.9 \%$ of COPD patients whereas their use is not approved at all by the Italian health minister in these patients.

In conclusion, this data suggests that in Italy the morbidity of asthma and COPD remains high; representing a significant economic burden for the Italian National Health Service. There is a clear necessity for further studies to investigate the causes of this incomplete control.

Acknowledgements: We would like to warmly thanks all the Italian general practitioners involved in this study. 


\section{References}

1. Dal Negro R, Berto P, Tognella S, Quareni L. Global Outcomes in Lung Disease Study Group. Cost-of-illness of lung disease in the TriVeneto Region, Italy: the GOLD Study. Monaldi Arch Chest Dis 2002; 57: 3-9.

2. Dal Negro R, Rossi A, Cerveri I. The burden of COPD in Italy: results from the Confronting COPD survey. Respir Med 2003; 97 (Suppl C): S43-S50.

3. de Marco R, Cerveri I, Bugiani M, Ferrari M, Verlato G. An undetected burden of asthma in Italy: the relationship between clinical and epidemiological diagnosis of asthma. Eur Respir J 1998; 11: 599-605.

4. de Marco R, Bugiani M, Cazzoletti L, et al. ISAYA study group. The control of asthma in Italy. A multicentre descriptive study on young adults with doctor diagnosed current asthma. Allergy 2003; 58: 221-228.

5. Global Initiative for Asthma. Global strategy for Asthma Management and Prevention. NHLBI/WHO Workshop report. 2002. NIH Publication No 02-3659: 1-200. Last update 2006. Freely available online at http://www.ginasthma.com (accessibility verified 6 April 2007). The Italian translation is freely available online at http://www.ginasma.it

6. Global Initiative for Chronic Obstructive Lung Disease. Global Strategy for the Diagnosis, Management and Prevention of Chronic Obstructive Pulmonary Disease. NHLBI/WHO workshop report. Bethesda, National Heart, Lung and Blood Institute, April 2001; NIH Publication No 2701: 1-128. Last update 2006. Freely available online at http://www.goldcopd.com (accessibility verified 6 April 2007). The Italian translation is freely available online at http://www.goldcopd.it

7. Caramori G, Bettoncelli G, Tosatto R, et al. Underuse of spirometry by general practitioners for the diagnosis of COPD in Italy. Monaldi Arch Chest Dis 2005; 63: 6-12.

8. Vermeire PA, Rabe KF, Soriano JB, Maier WC. Asthma control and differences in management practices across seven European countries. Respir Med 2002; 96: 142-149.

9. O'Connor PJ. Adding value to evidence-based clinical guidelines. JAMA 2005; 294: 741-743.

10. Tinelli C, Rezzani C, Biino G, et al, Evaluation of the efficacy of the Italian guidelines on COPD: a cluster randomized trial. Monaldi Arch Chest Dis 2003; 59: 199-206.

11. Cerveri I, Locatelli F, Zoia MC, Corsico A, Accordini $\mathrm{S}$, de Marco R. International variations in asthma treatment compliance: the results of the European Community Respiratory Health Survey (ECRHS). Eur Respir J 1999; 14: 288-294.

12. Anthonisen NR, Woodlrage K, Manfreda J. Use of spirometry and respiratory drugs in Manitobans over 35 years of age with obstructive lung diseases. Can Respir $J$ 2005; 12: 69-74.

13. Contoli M, Caramori G, Mallia P, Johnston S, Papi A. Mechanisms of virus-induced asthmatic exacerbations. Clin Exp Allergy 2005: 35: 137-145.

14. Rennard SI. Treatment of stable chronic obstructive pulmonary disease. Lancet 2004; 364: 791-802. 
Appendix 1. - English translation of the questionnaire

for the physician used in the study.

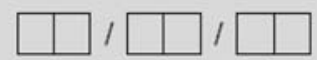

\section{CORD-IS B PROJECT}

\section{RESEARCH ON THE OUTCOME OF OBSTRUCTIVE RESPIRATORY DISEASE IN GENERAL PRACTICE}

\section{For the doctor}

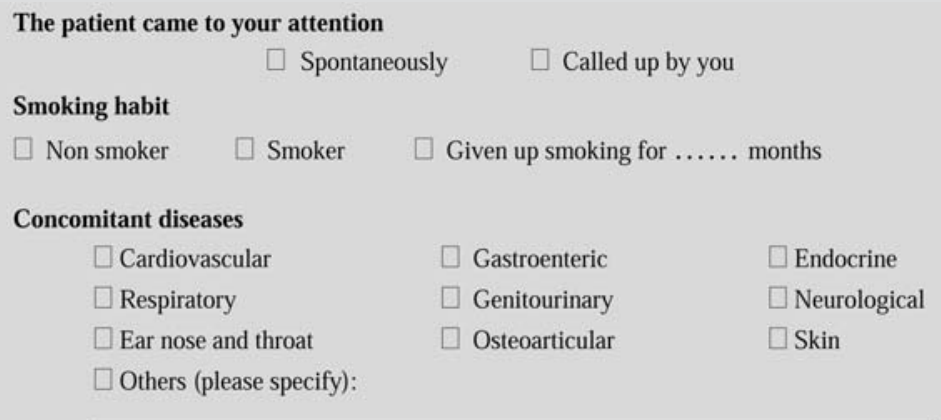

$\begin{array}{lll}\square \text { Cardiovascular } & \square \text { Gastroenteric } & \square \text { Endocrine } \\ \square \text { Respiratory } & \square \text { Genitourinary } & \square \text { Neurological } \\ \square \text { Ear nose and throat } & \square \text { Osteoarticular } & \square \text { Skin } \\ \square \text { Others (please specify): } & \end{array}$

Has the patient ever undergone a spirometry?

$$
\square \text { YES } \square \text { NO }
$$

Has the patient ever had a skin prick test?

$$
\square \text { YES } \square \text { NO }
$$

Diagnosis of the patient (both asthma and COPD can be selected simultaneously)
$\square$ ASTHMA
COPD

$$
\begin{aligned}
& \square \text { Intermittent } \\
& \square \text { Mild persistent } \\
& \square \text { Moderate persistent } \\
& \square \text { Severe persistent } \\
& \square \text { Staging not assessed }
\end{aligned}
$$
$\square$ Mild

\begin{tabular}{|c|c|c|c|}
\hline \multicolumn{2}{|c|}{ N. of packs } & \multicolumn{2}{|c|}{ N. of packs } \\
\hline$\square$ Short-acting $B_{2}$ agonists & $\square \square$ & $\square$ Antihistamines & $\square \square$ \\
\hline$\square$ Short-acting $B_{2}$ agonists/steroid & $\square \square$ & $\square$ Antileukotrienes & $\square$ \\
\hline$\square$ Short-acting $B_{2}$ agonists/anticholinergic & $\square \square$ & $\square$ Long-acting $B_{2}$ agonists & $\square \square$ \\
\hline$\square$ Teophylline & $\square \square$ & $\square$ Inhaled steroids & $\square$ \\
\hline$\square$ Oral steroids & $\square \square$ & $\square$ Injected steroids & $\square \square$ \\
\hline$\square$ Nasal steroids & $\square \square$ & $\square$ Mucolytics & $\square \square$ \\
\hline$\square$ Cromones & $\square \square$ & $\square$ Anticholinergics & $\square \square$ \\
\hline $\begin{array}{l}\square \text { Combinations in a single inhaler of } \\
\text { long-acting } B_{2} \text { /inhaled steroids }\end{array}$ & $\square \square$ & $\square$ Oral antibiotics & $\square \square$ \\
\hline
\end{tabular}
$\square$ Moderate
$\square$ Severe
$\square$ Staging not assessed

\section{$\square$ CHRONIC OBSTRUCTIVE RESPIRATORY DISEASE NOT BETTER IDENTIFIED}

$\begin{array}{ll}\text { Criterion used for the staging of asthma } & \text { Criterion used for the staging of COPD } \\ \square \text { Frequency of symptoms } & \square \text { Frequency of symptoms } \\ \square \text { Severity of airflow obstruction } & \square \text { Severity of airflow obstruction } \\ \square \text { Both } & \square \text { Both }\end{array}$

Treatment prescribed to the patient for chronic bronchial obstructive disease during the 12 months prior to the current visit:

Consumption of health resources (related to his/her chronic bronchial obstructive disease) during the 12 months prior to the current visit: Number of hospital admissions

Number of admissions to the emergency room Number of admissions to the Intensive Care Unit Number of specialist visits

In your opinion, how would you define the general health of the patient?
$\square$ Excellent
$\square$ Very good
$\square$ Good
Acceptable
$\square$ Poor 